\title{
Analysis of Indonesian Motorcycle Gang with Social Network Approach
}

\author{
Edi Surya Negara* ${ }^{1}$, Ria Andryani ${ }^{2}$, Deni Erlansyah ${ }^{3}$, Rezki Syaputra ${ }^{4}$ \\ Data Science Interdisciplinary Research Center, Faculty of Computer Science \\ Universitas Bina Darma, Palembang, Indonesia
}

\begin{abstract}
Analysis of motorcycle gang networks in Indonesia was conducted to determine the dynamics of the motor gang network. This analysis is needed by the government in making appropriate and effective policies in overcoming social problems caused by the existence of this group. The purpose of this study is to detect and determine the community structure of motorcycle gang networks in Indonesia through the use of big data available on the internet, especially social media. This research also utilizes several approaches such as social and behavioral sciences, as well as the computer technology in understanding and finding solutions to problems that arise in society. This study uses a social network analysis method as an instrument that will reveal the social structure of motorcycle gangs with a network centrality approach and community detection. This research succeeded in finding the network structure pattern and network insight of motorcycle gangs by finding the most influential actors. The study also found 25 motorcycle gang groups with high-value network interactions and these groups had more than 2000 active members on social media. In the biker gang social network analysis, the most influential actor has 531 degrees with a weighted degree of 1557 .
\end{abstract}

Keywords-Social network; data mining; data analytics; community detection; motorcycle gang

\section{INTRODUCTION}

As of December 2018, the Republic of Indonesia Police Traffic Corps data recorded that 120.1 million units of motorbikes were circulating in the community. Some motorcycle users build motorcycle groups or clubs. The majority of these groups are law-abiding members of the community and are not involved in illegal activities, but a small number are involved in activities that disturb public order and even lead to criminal acts that are carried out in groups or organized. This group of motorcycle riders who have a tendency to carry out activities that disturb public order and break the law is known in Indonesian society by the name of the motorcycle gang.

The criminal case of motorcycle gang members as a social phenomenon requires an in-depth social study as the basis for determining government policy for the prevention and control of crime. Experience in several countries such as the United States, Canada, Australia, and New Zealand shows that groups of motorcyclists who initially only disturbed public order easily turned into Outlaws Motorcycle Gang which is a criminal organization involved in the business of prostitution, human trafficking, arms smuggling, narcotics and drugs, and other serious crimes [1], [2], [3]. The fact that Indonesia is in a narcotics emergency, is not impossible if the motorcycle gang

\footnotetext{
*Corresponding Author
}

will interact and collaborate with other criminal organizations. To prevent the motorcycle gang which was originally a youth delinquency group transformed into a criminal organization, appropriate and effective policies and responses are needed to anticipate this threat. Furthermore, appropriate and effective policies and responses require an understanding of the behavior, structure of social networks [4], [5], and group dynamics of the motorcycle gang [6].

The increasing number of criminal problems caused by crimes committed by motorcycle gangs is of concern to the government. So that a special approach is needed to be able to provide solutions to these problems. The main problem of this research is how to find out the structure of the social network of motorcycle gang groups in Indonesia. In addition, this research can also provide an overview of how the growth patterns of motorcycle gang groups in Indonesia.

To measure the structure of social networks and group dynamics, a social network analysis approach can be used. In general, a network is a relationship of two or more objects where the object is denoted by a node and the relation between objects is denoted by an edge. The representation of objects on the network can be in the form of people called social networks and the representation of relations can be in the form of social relations such as friendship [20]. Social networks are social relationships between individuals or groups that interact with each other. This relationship can be a relationship between individuals and individuals, individuals with groups, or groups with groups [7], [8]. Social Network Analysis is a study that is used to look at human social relations through graph theory [9]. Through graph theory, social network analysis can find out the structure of social relations in certain groups through degree centrality and community detection. The main task of social networking analysis is to identify the most influential actors in a social network using statistical measures [10].

Degree Centrality is a measure in the graph used in network analysis to find important structures of vertices and edges. Centrality generally determines the importance of a node-based only on the structure of the graph. The simplest definition of node centrality is that the central node must be the most active node or the node that has the most ties with other nodes in the network [11]. The formula used to calculate the degree of centrality of a node in a graph can be done using the formula in equation (1). Where $d(n i)$ is the number of relations that a node has with another node in the graph.

$$
C D(n i)=d(n i)
$$


Community detection is one method of social network analysis in detecting communities on a network. Implicitly the definition of community refers to the structure of the network is a group of vertices that are connected to one another with certain proximity and density that have similarities in the network. A community, also known as a cluster, is usually considered a group of nodes that have many connections to each other and multiple connections to the entire network. Identifying communities in a network can provide valuable information about the structural properties of the network, interactions between nodes in the community, and the role of nodes in each community [6]. To detect communities on social networks, the formula modularity can be used. Modularity shows how relationships that exist on social networks can form different groups in a social network. The modularity formula can be seen in equation (2). Where $Q$ is modularity, $e_{i i}$ is probability edge is in module $i$, and $a_{i}^{2}$ is probability a random edge would fall into module.

$\mathrm{Q}=\sum_{1=1}^{k}\left(e_{i i}-a_{i}^{2}\right)$

Improved social network analysis methods are characterized by the ability to identify. Using techniques such as block modeling can reveal interactions between groups and between criminal networks by determining the presence or absence of associative bonds, identifying networks involved in one or more criminal activities, and then identifying relationships between groups or individuals (chain structure) that will be seen through clustering [15]. Subgroups, leaders, group members, main leaders are identified through degrees, interactions, and closeness [12]. Social networking analysis is the main tool used in studying and investigating criminal organizations and radical groups [13], [14].

In this study, we used a social network analysis approach using data from the social networking site Facebook. Facebook data is used because currently Facebook is the social media platform with the largest number of users compared to other social media platforms. There are four important reasons that use the social network analysis approach to study the dynamics and social networks of motorcycle gang groups in Indonesia. First, based on the nature and social behavior of the motorcycle gang analysis social networking is a very suitable method for studying the behavior and dynamics of this group. Second, the demographics of motorcycle gang members who average age 15-18 years [16] are included in the age of active users of social media. The demographics of motorcycle gang members who are a subset of active social media user demographics enable the use of social network analysis techniques, not only as data collection techniques for analyzing motorcycle gang network phenomena but also to analyze, monitor, and even stimulate the dynamics of motorcycle gang groups. Third, the number of users of social networks in Indonesia. Indonesia is currently the country with the fourth-largest number of Facebook users in the world, with 60.3 million users in May 2014. The chances of a motorcycle gang member who is also an active Facebook user are huge. Fourth, modern computers that have high-performance memory and processor. Although social network analysis was first developed in the 1930s it can only be applied to analyze social problems involving real networks with a large number of actors about two decades ago because there are no computers that have memory and processors that can handle the complexity of the problem that must be resolved. A large number of motorcycle gang members using social media provides an opportunity to see patterns, social network structures that occur among group members by utilizing social networking analytical methods.

In contrast to research on social problems that use the science of sociology, criminology, or conventional psychology that relies on data collection using surveys or ethnography to uncover the effects and causes of these problems, this study uses the social networking paradigm. Analysis of social networks provides an alternative view where the attributes possessed by individuals are reduced compared to relationships and bonds with other actors who are in the network. Analysis of social networks has been used to explain social phenomena and organizational behavior see [16],[17] and bibliography therein.

In this article, it is explained about the social network structure of motorcycle gangs in Indonesia, where the data used in this study is the data of motorcycle gangs from several cities in Indonesia, namely: Jakarta, Bandung, and Palembang. The reason for choosing motorcycle gangs from the cities of Jakarta, Bandung, and Palembang as a dataset to be analyzed is due to simple content analysis on Indonesian-language online news sites about motorcycle gang activity from 2012 2020 the three cities are often recorded on online news sites related to actions criminal motorcycle gang [18]. The analysis of social networks will provide insights into central actors with the degree centrality method and community detection with the modularity method [19], [6].

\section{RESEARCH METHOD}

Analysis of Indonesia Motorcycle Gang with Social Network Approach. This study consists of four iterative stages, namely Data Collection, Data Processing, Network Analysis, and Graph Visualization. The flow of the research process can be seen in Fig. 1.

\section{A. Data Collection}

This research uses data sourced from Facebook. The data taken is Facebook Fanpage data from the motorcycle community in the cities of Jakarta, Bandung, and Palembang. Data retrieved with web crawling techniques using the Netvizz application. Netvizz is an application that functions to extract data from the Facebook platform. Data attributes in this study are Member_ID, Label, Type_Post, and Comment. To build a motorcycle gang community data network, the "Member_ID" attribute will be denoted as a node, then the "status" attribute will be denoted as the edge. Data representation of motorcycle gang network groups can be seen in Fig. 2. Data generated from this process can be seen in Table I.

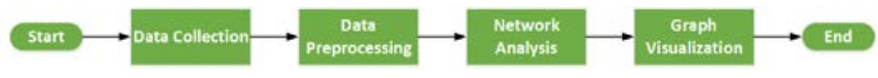

Fig. 1. Process Flow Research Stages. 


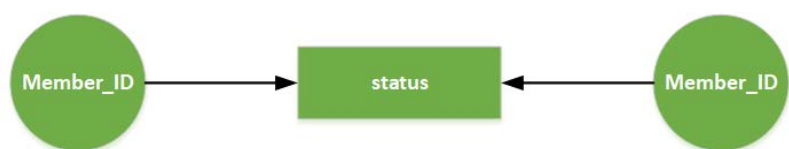

Fig. 2. Network representation of Indonesian Motorcycle Gang Community.

TABLE I. NUMBER OF DATA

\begin{tabular}{|l|l|l|}
\hline Data Source & Number of Node & Number of Edge \\
\hline Jakarta & 2126 & 5730 \\
\hline Bandung & 2138 & 4087 \\
\hline Makasar & 1297 & 4295 \\
\hline
\end{tabular}

\section{B. Data Preprocessing}

At this stage the data will be cleared by removing rows of no value, transforming the Member_ID, label, Type_Post, and Comment attribute to numeric, removing the leading and ending spaces, deleting all punctuation, changing all letters into lowercase letters, and repeating "FOR" To add a new line according to the number of" Comments "owned by the node. Fig. 3 shows some of the data that has been cleared at the data preprocessing stage.

\section{Network Analysis}

The formulation and formation of the motorcycle gang network is the first step that must be done before conducting network analysis. In social networks, there are two forms of relationships that occur namely: interconnection and interaction. Interconnection networks are formed by a node connection that is part of the same group in a network. Network interaction is formed from node relationships that occur based on communication interactions between nodes in the network through chat and respot to posts.

After the network is formed, the next step is to conduct a motorcycle gang network analysis. To conduct an analysis, this study uses the degree centrality, betweenness centrality, closeness centrality and community detection algorithms on social networks to find out the central actors or actors who have a big influence on the motorcycle gang, and recognize the motorcycle gang community in Indonesia based on recording interconnection and interaction happened to social media.

To analyze the social network of motorcycle gangs in Indonesia, iteratively, the framework or stages of analysis are built on the basis of the centrality and community detection analysis approach. In detail, these steps are shown in Fig. 4.

\section{Graph Visualization}

At this stage, the data that has gone through the preprocessing and processing stages will then be visualized using graphs, with the size discussed in the previous chapter, namely degree centrality, betweenness centrality, closeness centrality, and community detection. At this stage, you will also find the most influential node in the graph. Visualization is done using Gephi Graph Visualization 0.9.2 software.

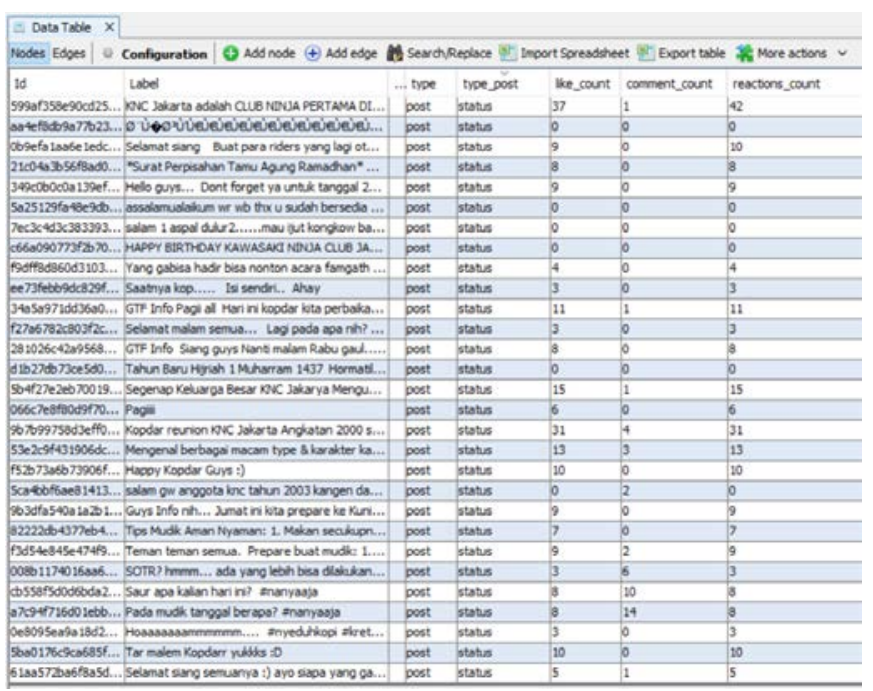

Fig. 3. Clean Dataset of the Indonesian Motorcycle Gang Community.

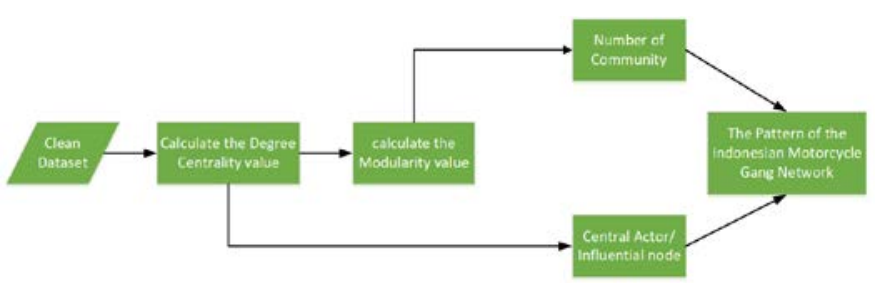

Fig. 4. Method for Network Analysis of Indonesia Motorcycle Gang Community.

\section{RESUlt AND Discussion}

Analysis conducted on the motorcycle group network conducted in this study has been able to produce a pattern of motorcycle gang social networks in Indonesia with some insights generated from these patterns. The insights generated from the network analysis are the central actors in the motorcycle gang through the degree centrality algorithm and this analysis also finds groups of motorcycle gangs in Indonesia through interconnection studies and interactions of each member through the community detection algorithm.

\section{A. Degree Centrality}

To measure the central actor of a node in a network can use the Degree Centrality. The results of calculating the centrality of the top 5 nodes can be seen in Table II.

Member_ID afb4c17f761de7e2546b764be5b30fca3132e8b has the highest centrality value with 531 degree. This can be interpreted that the actor is an actor who is in the motorcycle gang community is quite active in interaction through other user posts. In addition, high centrality values can also be found in the "post" variable. This can be interpreted that posts in the form of "status" submitted by the user get a high response through "comment" replies from other users. Visual graph based on Degree Centrality can be seen in Fig. 5. 
TABLE II. CENTRALITY DEgREE VALUE

\begin{tabular}{|l|l|l|l|l|}
\hline Member_ID & Type & $\begin{array}{l}\text { Type_- } \\
\text { Post }\end{array}$ & Degree & $\begin{array}{l}\text { Weighted } \\
\text { Degree }\end{array}$ \\
\hline $\begin{array}{l}\text { fafb4c17f761de7e2546b764 } \\
\text { be5b30fca3132e8b }\end{array}$ & User & User & 531 & 1557.0 \\
\hline $\begin{array}{l}\text { 37ca158055c0c4c39dea1287 } \\
\text { 77c2f9a5d81c21de }\end{array}$ & User & User & 299 & 470.0 \\
\hline $\begin{array}{l}\text { 920ac5756fd6bce87613879f } \\
\text { 058203878492caaf }\end{array}$ & Post & Status & 287 & 293.0 \\
\hline $\begin{array}{l}\text { 62c1bbb3c4b26ec6ae49dc65 } \\
\text { b883bbe789de61ca }\end{array}$ & User & User & 276 & 475.0 \\
\hline $\begin{array}{l}\text { 1fe624bab07d77e915f27c1a } \\
\text { e8babd16ad7eccb7 }\end{array}$ & User & User & 189 & 329.0 \\
\hline
\end{tabular}

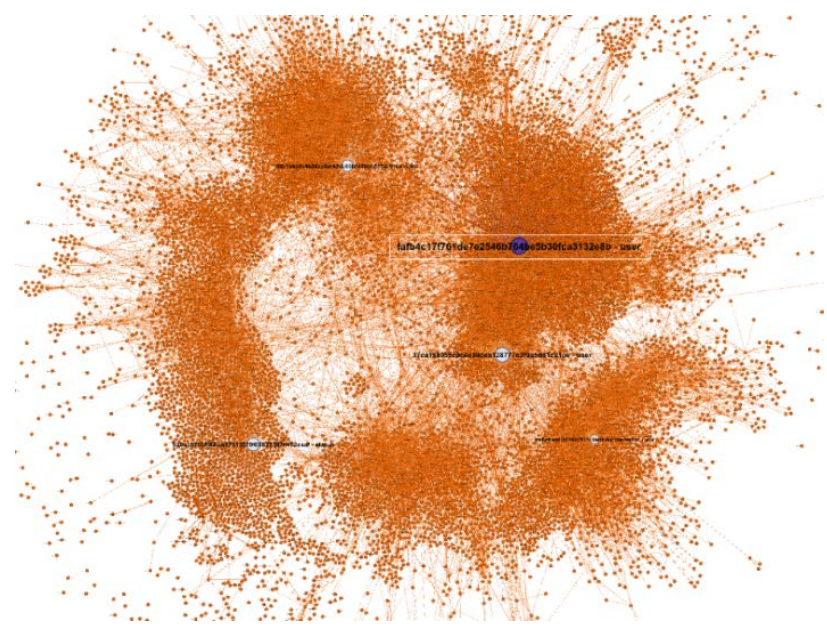

Fig. 5. Graph Visualization based on Degree Centrality.

\section{B. Betweenness Centrality}

This measure can be used to measure the influence of nodes in the network. From the popularity level it is known that the most popular node in the network is the node with Member_ID fafb4c17f761de7e2546b764be5b30fca3132e8b. The node with the highest betweenness centrality value because this node is a connecting node or hub between other cluster networks in the network. The most influential node in the motorcycle gang community is the node with Member_ID 37ca158055c0c4c39dea128777c2f9a5d81c21de. This can be proven by the results of the measurement of Betweenness Centrality in Table III. Node with Member_ID 37ca158055c0c4c39dea128777c2f9a5d81c21de which is the best link between the other nodes. This node has the most influence on other nodes. Visual results can be seen in Fig. 6.

\section{Closeness Centrality}

In this study, the graph used is an undirect graph. Then the Closeness calculation does not include InCloseness and OutCloseness. The results of calculating the Closeness Centrality value and Harmonic Closeness of the top five nodes can be seen in Table IV. The closeness centrality measure in this study aims to measure the centrality in the network, where the centrality measure is calculated as the inverse of the total length of the shortest path between the node and all other nodes in the graph. Harmonic centrality is a variant of closeness centrality that was invented to solve the problem the original formula had when dealing with unconnected graphs.

From the table above it can be seen that the highest closeness value is the node with Member_ID 37ca158055c0c4c39dea128777c2f9a5d81c21de, and the difference in closeness value between nodes in Table IV is not much different. This shows that the node with id has a high closeness value with other nodes, with the interpretation that the node is able to interact quickly with many other nodes. The closeness centrality value can be interpreted as a measure of the closeness between one user and another on the motorcycle gang network based on the average length of one user to all users in the network.

\section{Community Detection}

Based on its definition that a community is a social group that shares an environment, a group can be interpreted as a collection of individuals. Therefore, to be able to meet these criteria, filtering is needed for nodes that have no relationship with other nodes (standalone). Node filtering uses the degree range in the gephi application to filter nodes that have no relationship, after which modularity calculations are performed to detect the community. Then the modularity calculation results obtained by 0.771 and the number of communities as much as 25 with a minimum degree range 1 . The results can be seen in Fig. 7.

TABLE III. BetweENNESS CENTRALITY VALUE

\begin{tabular}{|l|l|l|l|}
\hline Member_ID & Type & Type_Post & $\begin{array}{l}\text { Betweenness } \\
\text { Centrality }\end{array}$ \\
\hline $\begin{array}{l}\text { 37ca158055c0c4c39dea12 } \\
\text { 8777c2f9a5d81c21de }\end{array}$ & User & User & $\begin{array}{l}1.10287310762161 \\
02 \mathrm{E} 7\end{array}$ \\
\hline $\begin{array}{l}\text { fafb4c17f761de7e2546b76 } \\
\text { 4be5b30fca3132e8b }\end{array}$ & User & User & $\begin{array}{l}8533454.16527957 \\
1\end{array}$ \\
\hline $\begin{array}{l}\text { 62c1bbb3c4b26ec6ae49dc } \\
\text { 65b883bbe789de61ca }\end{array}$ & User & User & $\begin{array}{l}3565699.07313252 \\
7\end{array}$ \\
\hline $\begin{array}{l}\text { 920ac5756fd6bce8761387 } \\
\text { 9f058203878492caaf }\end{array}$ & Post & Status & $\begin{array}{l}3113989.78757254 \\
45\end{array}$ \\
\hline $\begin{array}{l}\text { ffdc0a318547cb46436b56 } \\
\text { 8fdde11538f7bb0308 }\end{array}$ & User & User & $\begin{array}{l}3103838.98698050 \\
44\end{array}$ \\
\hline
\end{tabular}

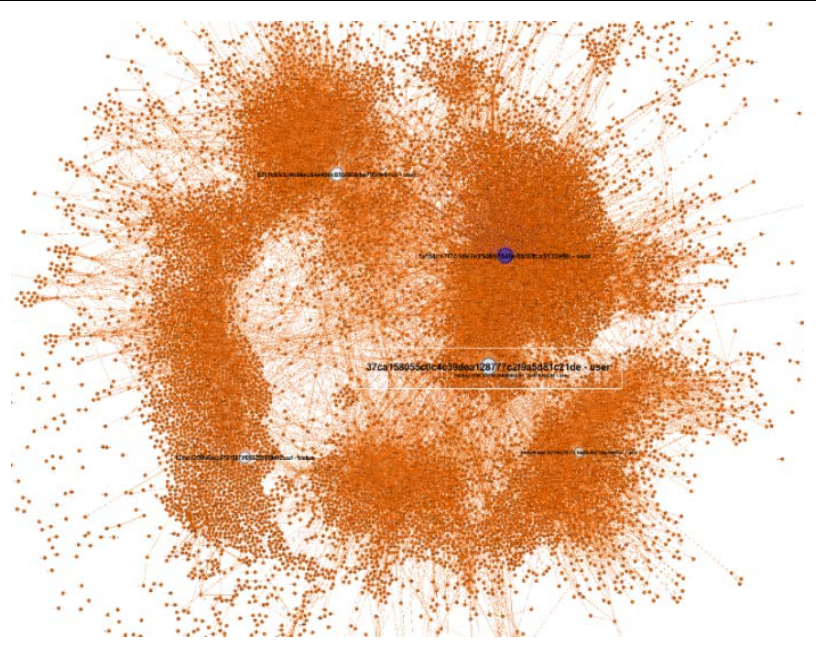

Fig. 6. Graph Visualization based on betweenness Centrality. 
TABLE IV. Closeness CEnTRALity VAlue

\begin{tabular}{|l|l|l|}
\hline Member_ID & $\begin{array}{l}\text { Closeness } \\
\text { Centrality }\end{array}$ & $\begin{array}{l}\text { Harmonic } \\
\text { Closeness }\end{array}$ \\
\hline $\begin{array}{l}\text { 37ca158055c0c4c39dea128777c } \\
\text { 2f9a5d81c21de }\end{array}$ & 0.293624 & 0.335476 \\
\hline $\begin{array}{l}\text { fafb4c17f761de7e2546b764be5b } \\
\text { 30fca3132e8b }\end{array}$ & 0.27157 & 0.326414 \\
\hline $\begin{array}{l}\text { 189d8fa179d15fc843283744099 } \\
\text { 722ba1db46609 }\end{array}$ & 0.268945 & 0.292587 \\
\hline $\begin{array}{l}\text { ba9a4aa1b36216f9560358e38fee } \\
\text { 246625467b41 }\end{array}$ & 0.26634 & 0.293028 \\
\hline $\begin{array}{l}\text { 6f0fdfc005a5c10625580b88d6f2 } \\
\text { a6caec69591b }\end{array}$ & 0.263916 & 0.289941 \\
\hline
\end{tabular}

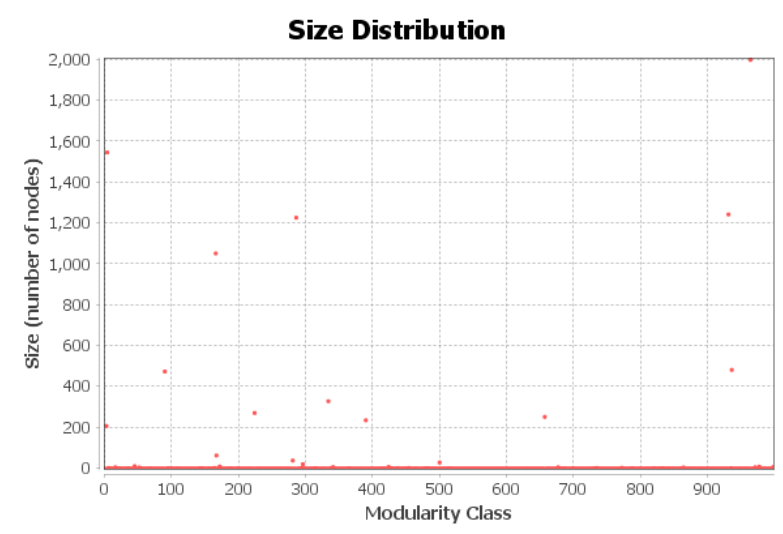

Fig. 7. Modularity Class.

From Fig. 7 it can be seen that the largest community is class 25 with the highest number of nodes or more than 2000 nodes. Fig. 7 is generated from the visualization of the results of community calculations on the motorcycle gang dataset using the modularity algorithm approach. The results of the community with 25 classes are community clusters that have been generated from the calculation of modularity where the number of nodes in the class is 2000 users. The picture shows several communities with different color labels for each community. More color distribution at the node shows the percentage of the number of community members or the number of nodes. The community graph can be seen in Fig. 8 .

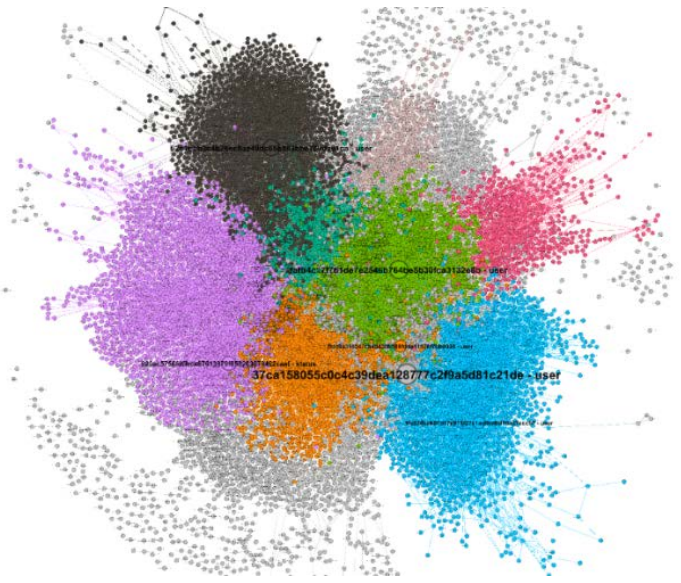

Fig. 8. Visualization of Motorcycle Gang Community Networks.

\section{CONCLUSION}

Analysis of the social network of motorcycle gangs in Indonesia has succeeded in providing knowledge about the structure of social networks and providing insights from existing motorcycle gang networks in Indonesia. This research has been able to provide important information for the government in solving the problem of motor gang crime through a social network analysis approach. This analysis finds the most influential actors in the motorcycle gang through high centrality and interaction values. The study also found 25 motorcycle gang groups with high-value network interactions and these groups had more than 2000 active members on social media. In a motorcycle gang, according to the analysis of social networks, the most influential actor has 531 degrees with a weighted degree of 1557 . This shows that the actor is the central actor.

Suggestions for the next research are to increase the amount of data to be analyzed using data from various other social media platforms. In addition, another challenge that needs to be resolved is to analyze the motorcycle gang network in real-time using a machine learning approach.

\section{REFERENCES}

[1] J. F. Quinn, “Angels, bandidos, outlaws, and pagans: The evolution of organized crime among the big four $1 \%$ motorcycle clubs," Deviant Behavior, vol. 22, no. 4, pp. 379-399, 2001.

[2] J. Quinn and D. Shane Koch, "The nature of criminality within one percent motorcycle clubs,” Deviant Behavior, vol. 24, no. 3, pp. 281305, 2003.

[3] D. Shields, “The infamous 'one percenters': A review of the criminality, subculture, and structure of modern biker gangs,” Justice Policy Journal, vol. 9, no. 1, pp. 1-33, 2012.

[4] D. N. S. Diah Novita Sari, S. Dedy, and E. S. Negara, "Structure community analysis on social network," in The 6th International Conference on Information Technology and Business Application (ICIBA2017), vol. 1. Penerbit: Pusat Penerbitan dan Percetakan Universitas Bina Darma Press PPP, 2017, pp. 1-7.

[5] A. isnaini Sugiarta, E. S. Negara et al., "Analisis sentralitas aktor pada struktur jaringan politik dengan menggunakan metode social network analysis (sna): Studi kasus group facebook lembaga survei sosial media," in Seminar Nasional Teknologi Informasi dan Komunikasi (SEMNASTIK), vol. 1, no. 1, 2018, pp. 203-209.

[6] E. S. Negara and R. Andryani, “A review on overlapping and non overlapping community detection algorithms for social network analytics,” Far East Journal of Electronics and Communications, vol. 18, no. 1, pp. 1-27, 2018.

[7] C. K.-S. Leung, I. J. Medina, and S. K. Tanbeer, "Analyzing social networks to mine important friends,” in Social media mining and social network analysis: Emerging research. IGI Global, 2013, pp. 90-104.

[8] M. Ria Andryani, M. Kom, M. Ria Andryani, M. Kom, S. N. Edi et al., "Network of friends to the other friends by social media on facebook," The Turkish Online Journal of Design, Art and Communication, vol. 12, no. 12, pp. 1363-1378, 2017.

[9] M. Tsvetovat and A. Kouznetsov, Social Network Analysis for Startups: Finding connections on the social web. " O’Reilly Media, Inc.", 2011.

[10] M. Cordeiro, R. P. Sarmento, P. Brazdil, and J. Gama, "Evolving networks and social network analysis methods and techniques,” Social Media and Journalism: Trends, Connections, Implications, vol. 101, no. 2, 2018.

[11] L. Freeman, “The development of social network analysis,” A Study in the Sociology of Science, vol. 1, p. 687, 2004.

[12] A. Sergi, “Case study 4: United kingdom and the activity model," in From Mafia to Organised Crime. Springer, 2017, pp. 177-213.

[13] A. Kriegler, "Using social network analysis to profile organised crime," Policy Brief, vol. 57, 2014. 
[14] G. Mastrobuoni and E. Patacchini, "Organized crime networks: An application of network analysis techniques to the american mafia," Review of Network Economics, vol. 11, no. 3, 2012.

[15] Y. Lu, X. Luo, M. Polgar, and Y. Cao, "Social network analysis of a criminal hacker community,” Journal of Computer Information Systems, vol. 51, no. 2, pp. 31-41, 2010.

[16] I. Tofail, “Tinjauan kriminologis terhadap kejahatan yang dilakukan oleh geng motor di kabupaten gowa,” Makassar: Skripsi Fakultas Hukum Universitas Hasanuddin, 2013.

[17] S. P. Borgatti, A. Mehra, D. J. Brass, and G. Labianca, "Network analysis in the social sciences,” science, vol. 323, no. 5916, pp. 892895, 2009.
[18] Kompas. (2020) Geng-motor. [Online]. Available: https://www.kompas. com/tag/geng-motor.

[19] D. F. Brianna, E. S. Negara, and Y. N. Kunang, "Network centralization analysis approach in the spread of hoax news on social media," in 2019 International Conference on Electrical Engineering and Computer Science (ICECOS). IEEE, 2019, pp. 303-308.

[20] Negara, E.S., Kerami, D., Wiryana, I.M., Maulana Kusuma, T.B. (2017), "Researchgate data analysis to measure the strength of Indonesian research”. Far East Journal of Electronics and Communications, 17(5), pp.1177-1183. 